\title{
Blending octane number of toluene with gasoline-like and PRF fuels in HCCI combustion mode
}

\author{
Author, co-author (Do NOT enter this information. It will be pulled from participant tab in MyTechZone)
} Affiliation (Do NOT enter this information. It will be pulled from participant tab in MyTechZone)

\begin{abstract}
Future internal combustion engines demand higher efficiency but progression towards this is limited by the phenomenon called knock. A possible solution for reaching high efficiency is Octane-on-Demand (OoD), which allows to customize the antiknock quality of a fuel through blending of high-octane fuel with a low octane fuel. Previous studies on Octane-on-Demand highlighted efficiency benefits depending on the combination of low octane fuel with high octane booster. The author recently published works with ethanol and methanol as high-octane fuels. The results of this work showed that the composition and octane number of the low octane fuel is significant for the blending octane number of both ethanol and methanol. This work focuses on toluene as the high octane fuel (RON 120). Aromatics offers anti-knock quality and with high octane number than alcohols, this work will address if toluene can provide higher octane enhancement. Our aim is to investigate the impact of three gasolinelike fuels and two Primary Reference Fuels (PRFs). More specifically, fuels are FACE (Fuels for Advanced Combustion Engines) I, FACE J, FACE A, PRF 70 and PRF 84. A CFR engine was used to conduct the experiments in HCCI mode. For this combustion mode, the engine operated at four specific conditions based on RON and MON conditions. The octane numbers corresponding to four HCCI numbers were obtained for toluene concentration of $0,2,5,10,15$ and $20 \%$. Results show that the blending octane number of toluene varies nonlinearly and linearly with the increase in toluene concentration depending on the base fuel, experimental conditions and the concentration of toluene. As a result, the blending octane number can range from close to 150 with a small fraction of toluene to a number closer to that of toluene, 120 , with larger fractions.
\end{abstract}

\section{Introduction}

Higher thermal efficiency for Spark Ignition (SI) engines is mainly restricted due to knock [1]. The gasoline produced from the refineries have low octane rating [2]. The most popular choice for increasing the octane rating for the gasoline is by addition of aromatics and alcohols [3-5]. Alcohols such as ethanol and methanol are widely accepted because of their higher octane number and latent heat of vaporization. The addition of high octane fuel to a lower octane fuel can be done by both splash blending and customized blending. For the customized blending, the two fuels are blended in real time and the anti-knock quality of the final blend can be varied depending on the engine requirements. This method of blending is known as Octane on Demand (OoD).

Page 1 of 12
The knock rating of the fuel is experimentally performed using Cooperative fuel research (CFR) engine according to ASTM standards $[\underline{6,7]} . \mathrm{RON}$ and MON are two parameters that are used to understand the knocking behavior of the fuels [8]. The mixtures of $n$-heptane and iso-octane are known as Primary Reference Fuels (PRFs) []]. The octane number of the fuel is obtained by comparing its auto-ignition behavior with the PRF mixture. The sensitivity ( $=$ RON-MON) of the PRF mixture is zero by definition [1]. Commercial fuels used in vehicles do not have zero sensitivity and consist of many components such as aromatics, olefins, paraffins and oxygenates [9]. In order to introduce sensitivity and understand the auto ignition behavior of such fuels, toluene is used and one of the possible surrogate fuels for the commercial gasoline is toluene reference fuel (TRF) $[1,9,10]$. The toluene reference fuel consist of three components: toluene, $n$-heptane and iso-octane [11]

The RON of toluene was found to be 120 [11-13]. It has been previously shown that the addition of toluene to the base fuels (isooctane and n-heptane) resulted in a non-linear blending behavior of octane number with the increasing content of the toluene into the mixture $[11,14]$. The blending octane number $(\mathrm{BON})$ is used to describe the non-linear blending behavior [15-17]. Mathematically, the blending octane number is given by $[15,18]$ :-

$$
B O N(S I)=\frac{\text { RON }_{\text {mix }}-\text { RON }_{\text {base }} . C_{\text {base }}}{C_{\text {booster }}},(1)
$$

where $R O N_{b a s e}$ stands for the RON of the base fuel, $C_{\text {base }}$ is the concentration of the base fuel, $C_{\text {booster }}$ is the concentration of the booster and $R O N_{\text {mix }}$ is the octane number of the mixture (either vol. \% or mol. \% of the liquid phase). The RON term is replaced with the HCCI fuel number for HCCI conditions.

For the non-linear behavior to exists, the blending octane number has to be greater or less than the research and motor octane number of base fuel. It has been reported that the addition of toluene into iso-octane generates antagonistic blending effect for MON. However, for nheptane, synergistic blending behavior is observed for both RON and MON [11]. For the antagonistic blending behavior, the octane number of the mixture is lower than the octane number of base fuel $[14,18]$. This is opposite to the synergistic blending behavior when ethanol is added into iso-octane, n-heptane and the mixtures of both [14]. For synergistic blending behavior, the octane number of the mixture is higher than the base fuel octane number [18].

Homogeneous Charge Compression Ignition (HCCI) combustion mode is well known for its lower nitric oxides emissions and reduced fuel economy $[19,20]$. RON and MON are not considered to be ideal 
parameters to describe the auto-ignition behavior in HCCI but instead Lund-Chevron HCCI fuel number is used [21]. Previously the addition of toluene into ethanol reference fuels which consist of ethanol, isooctane and n-heptane have shown that the RON and HCCI number do not correlate well at both lower and higher inlet air temperatures [21].

The presence of aromatics in the gasoline fuel offers significant antiknock quality $[22,23]$. Previous studies by the author about the addition of ethanol and methanol have shown a strong non-linear blending behavior into the base fuels $[15,24,25]$. The blending octane number (BON) for ethanol was around 200 at small concentrations and at $100 \%$ ethanol concentration,, the BON decreased to 108 [15]. A synergistic blending effect was observed for the ethanol[15]. Small concentrations of ethanol were quite effective in increasing the octane number in a disproportional manner[15]. Base fuel composition and octane number changed the blending octane number significantly[15, 17].

The octane number of toluene is higher than the octane number of ethanol and methanol. This study will utilize toluene as an octane booster and determine if it can offer the same octane boosting benefits as previously found for ethanol and methanol. The base fuel composition has an important role in the non-linear RON evolution [14]. The presence of aromatics in the base fuel can significantly influence the RON response with the addition of octane booster. It has been reported that with the addition of octane booster such as ethanol into the base fuel having aromatics will lead to a decrease in the octane number [1]. Less is known about the role of toluene if its addition to the base fuel will cause a decrease in octane number in $\mathrm{HCCI}$ combustion mode. This study will determine whether the combustion mode has important role when toluene is added as octane booster. The role of base fuel composition and octane number in the HCCI fuel number evolution with toluene addition will also be determined. Five base fuels were chosen, of which two, FACE I and FACE J gasoline's, have similar RON close to 70 but the aromatic contents differ by $30 \%$. This will enable to understand the role of base fuel composition on blending octane number.

\section{Experimental Set up}

A Cooperative fuel research (CFR) engine was used to conduct the experiments in the lean combustion environment. It was a variable compression ratio engine with a range from 4 to 19 . The standard CFR engine is equipped with carburetor but for HCCI combustion, it was replaced by port fuel injector. The fuel was injected $5 \mathrm{~cm}$ away from the inlet valve using a constant feed fuel pressure of 6 bar. The intake air flow temperature was regulated using two electric heaters. The first electric heater was placed $75 \mathrm{~cm}$ away from the inlet valve and the other one $125 \mathrm{~cm}$ away. The in-cylinder pressure was measured using AVL GH14 D pressure transducer at a resolution of $0.2 \mathrm{CAD}$. The engine control and the data acquisition were carried using the LABVIEW software. Some of the engine specifications are shown in Table 2. Figure 1 shows the CFR engine used for the experiments.

Four different HCCI fuel numbers were defined for this study. Table 1 shows the experimental conditions for the four HCCI numbers. HCCI$1\left(600 \mathrm{rpm}, 52^{\circ} \mathrm{C}\right)$ and $\mathrm{HCCI}-4\left(900 \mathrm{rpm}, 149^{\circ} \mathrm{C}\right)$ were defined equivalent to RON and MON of SI combustion mode. The other two were defined to investigate the effect of temperature (HCCI-2) and speed (HCCI-3) independently. Previously four HCCI fuel numbers were also defined experimentally by Truedsson et al and support this work [21].

Page 2 of 12
Table 1: Four HCCI fuel numbers

\begin{tabular}{|l|l|l|}
\hline HCCI fuel numbers & Engine speed (rpm) & $\begin{array}{l}\text { Intake air } \\
\text { Temperature } \mathrm{T}_{\text {in }}\left({ }^{\circ} \mathrm{C}\right)\end{array}$ \\
\hline HCCI-1 (RON) & 600 & 52 \\
\hline HCCI-2 & 600 & 149 \\
\hline HCCI-3 & 900 & 52 \\
\hline HCCI-4 (MON) & 900 & 149 \\
\hline
\end{tabular}

Table 2: Engine specifications and operating conditions

\begin{tabular}{|l|l|}
\hline Engine Type & Single Cylinder CFR \\
\hline Injection System & Port Fuel Injection \\
\hline Bore & $82.55 \mathrm{~mm}$ \\
\hline Stroke & $114.3 \mathrm{~mm}$ \\
\hline Connecting Rod & $254 \mathrm{~mm}$ \\
\hline Compression ratio & Variable from 4:1 to 15:1 \\
\hline Speed & $600-900 \mathrm{rpm}$ \\
\hline Intake Pressure & 1 bar \\
\hline Minimum Intake Air Temperature & $52 \pm 2{ }^{\circ} \mathrm{C}$ \\
\hline Maximum Intake Air Temperature & $149 \pm 2{ }^{\circ} \mathrm{C}$ \\
\hline Lambda $(\lambda)$ & $3(\mathrm{HCCI})$ \\
\hline
\end{tabular}

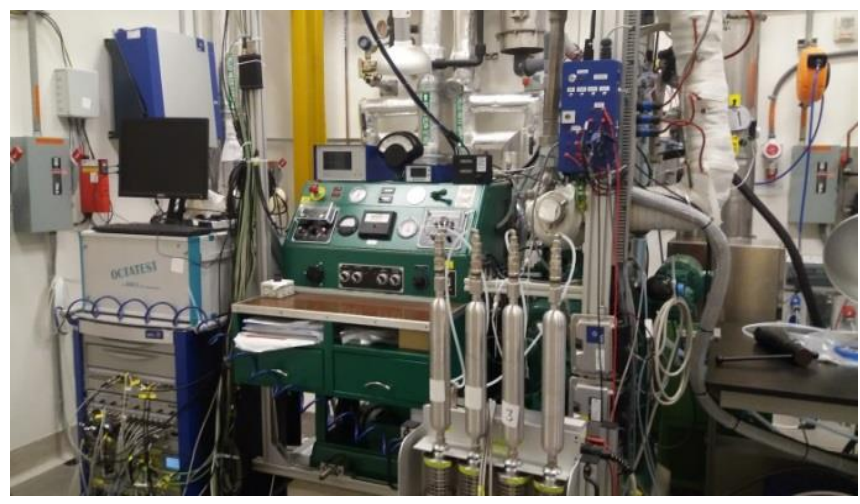

Figure 1: CFR engine. 


\section{Fuels}

Five base fuels consisting of three FACE gasolines FACE I, FACE J and FACE A and two PRF (Primary reference fuels) 70 and PRF 84 were used for this study. More details about the properties, ignition and heat release characteristics can be found in Ref [26-31]. Three of the base fuels (FACE I, J and PRF 70) are classified as low octane fuels with RON close to 70 and two other fuels (FACE A and PRF 84) as high octane fuels with RON closer to 84 . Toluene was added to these base fuels at a concentration of $0 \%, 2 \%, 5 \%, 10 \%, 15 \%$ and $20 \%$ by volume in liquid phase. Some of the details about the properties of the base fuels are shown in Table 3.

Table 3: Base fuel properties

\begin{tabular}{|l|l|l|l|l|l|}
\hline \multirow{2}{*}{ Fuels } & \multicolumn{3}{|c|}{ Low octane fuels } & \multicolumn{2}{c|}{$\begin{array}{c}\text { High octane } \\
\text { fuels }\end{array}$} \\
\cline { 2 - 6 } & $\begin{array}{c}\text { FACE } \\
\text { I }\end{array}$ & $\begin{array}{c}\text { FACE } \\
\text { J }\end{array}$ & $\begin{array}{c}\text { PRF } \\
\mathbf{7 0}\end{array}$ & $\begin{array}{c}\text { FACE } \\
\text { A }\end{array}$ & $\begin{array}{c}\text { PRF } \\
\mathbf{8 4}\end{array}$ \\
\hline RON & 70.2 & 73.8 & 70.0 & 83.9 & 84.0 \\
\hline MON & 69.5 & 70.1 & 70.0 & 83.5 & 84.0 \\
\hline Octane Sensitivity & 0.7 & 3.7 & 0.0 & 0.4 & 0.0 \\
\hline Aromatics (vol. \%) & 1.2 & 31.7 & 0.0 & 0.4 & 0.0 \\
\hline$n$-Paraffins (vol. \%) & 14.4 & 31.6 & 30.0 & 11.7 & 16.0 \\
\hline
\end{tabular}

\section{HCCI fuel number of blends}

It is well established that for SI combustion, RON and MON are the two parameters which are used to characterize the auto-ignition behavior [8]. For HCCI, these two parameters are not ideal and therefore Lund-Chevron HCCI number was introduced to understand the auto-ignition behavior of the fuels in lean combustion environment [21]. As a first step to obtain HCCI fuel numbers, PRF mixtures (PRF 60, PRF 70, PRF 80 and PRF 90) were tested and four transfer functions equivalent to four HCCI fuel numbers were obtained as shown in Figure 2. As expected, $h$ the increase in the intake air temperature, the compression ratios required for the auto-ignition decreased for each of the tested blends. The method to obtain the transfer function requires finding compression ratios for the autoignition of the PRF mixtures with CA50 (50\% heat released) of $3^{\circ}$ after TDC. A line of best fit was obtained for each of the HCCI fuel numbers which was further used to estimate the HCCI fuel number of the toluene blends. The line of fit was in quadratic form as given by:-

HCCI fuel number $=x R_{C}^{2}+y R_{C}+z(2)$

Where HCCI fuel number represents PRF (Iso-octane/n-heptane) mixtures $(60,70,80$ and 90$)$ tested and $R_{C}$ was the compression ratio. The compression ratios obtained from the toluene blends are used alongside the equation 2 to estimate the HCCI fuel numbers for the blends. The constant values for each of $\mathrm{x}, \mathrm{y}$ and $\mathrm{z}$ are given in the Appendix B for each of the HCCI conditions.

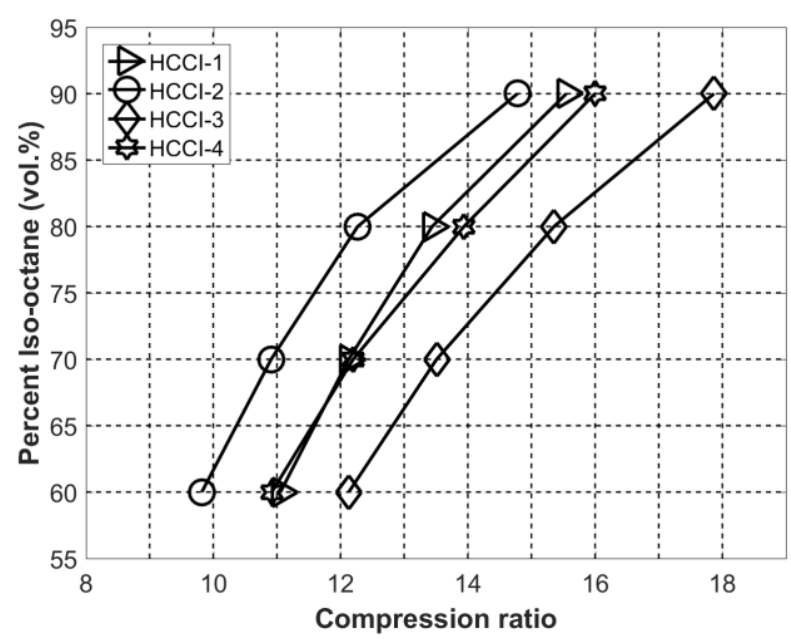

Figure 2: Transfer function in HCCI mode.

\section{Blending HCCI Fuel Number (BON)}

It has been highlighted in the previous publications of the author that the non-linear blending behavior can be described by the blending octane number (BON) [15, 18].

For HCCI mode, equation 1 can be expressed as:-

$B O N(H C C I)=\frac{H C C I_{\text {mix }}-H C C I_{\text {base }} . C_{\text {base }}}{C_{\text {booster }}}$, (3)

Where $\mathrm{HCCI}_{\text {base }}$ stands for HCCI fuel number for the base fuel $(0 \%$ toluene)

$C_{\text {base }}=$ Concentration of the base fuel (\%vol in liquid phase.)

$C_{\text {booster }}=$ Concentration of the booster $(\%$ vol in liquid phase. $)$

$H C C I_{\text {mix }}=$ HCCI fuel numbers of the toluene blends $(2 \%, 5 \%, 10 \%$, $15 \%, 20 \%$ vol in liquid phase.)

\section{Results}

\section{HCCI fuel number of different blends}

Five base fuels were tested in this study and toluene was added to these base fuels in volume percentage of $2 \%, 5 \%, 10 \%, 15 \%$ and $20 \%$. As described earlier, the HCCI fuel numbers for the blends were obtained from the transfer function, as shown in Figure 2.

Figure 3 illustrates the variation of HCCI fuel number \#1 with toluene. At this operating condition, the engine was running at $600 \mathrm{rpm}$ with an inlet air temperature of $52^{\circ} \mathrm{C}$, which is equivalent to the RON condition of SI. As expected, the addition of toluene resulted in the increase of HCCI fuel number. For the low ON fuels (FACE I, J and PRF 70), $20 \%$ addition resulted in the increase of HCCI fuel number from about 70 to 84. For the high ON fuels (FACE A and PRF 84), the increase in the HCCI fuel number was only from 84 to 88 . The missing data for the high $\mathrm{ON}$ fuel is due to the limitation of compression ratios from the engine hardware and as such, toluene could not be added beyond $10 \%$ by volume. 


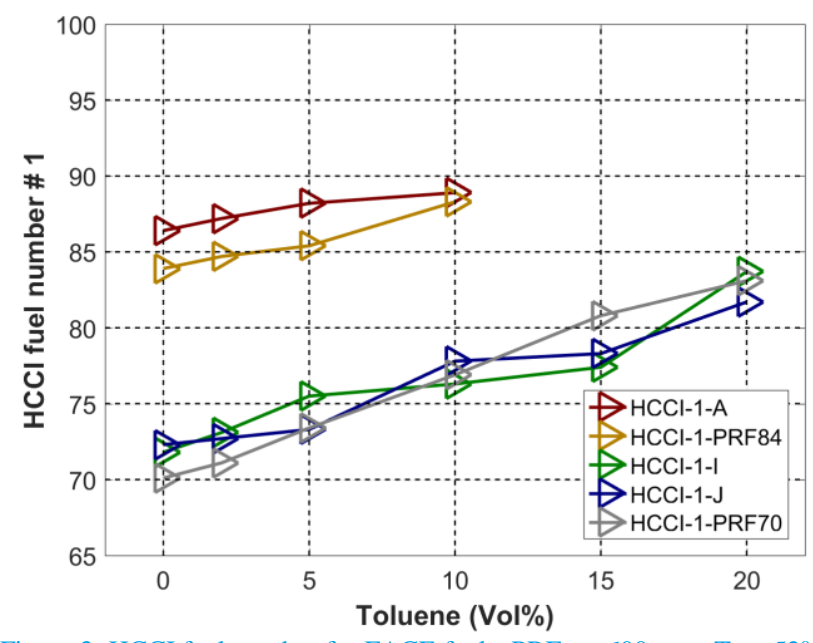

Figure 3: HCCI fuel number for FACE fuels, PRFs at $600 \mathrm{rpm}, \mathrm{T}_{\mathrm{in}}=52^{\circ} \mathrm{C}$ and $\lambda=3$.

Figure 4 shows the variation of HCCI fuel number \# 2 with toluene addition. At this operating condition, the engine was running at 600 $\mathrm{rpm}$ with an inlet air temperature of $149^{\circ} \mathrm{C}$. As expected, the trends for all the base fuels remain the same with the increase in HCCI fuel numbers for the base fuels. With the high inlet air temperature, the increase in HCCI fuel number has decreased with toluene addition, as compared to HCCI fuel number \# 1. This is true for all base fuels and can be observed from the slopes.

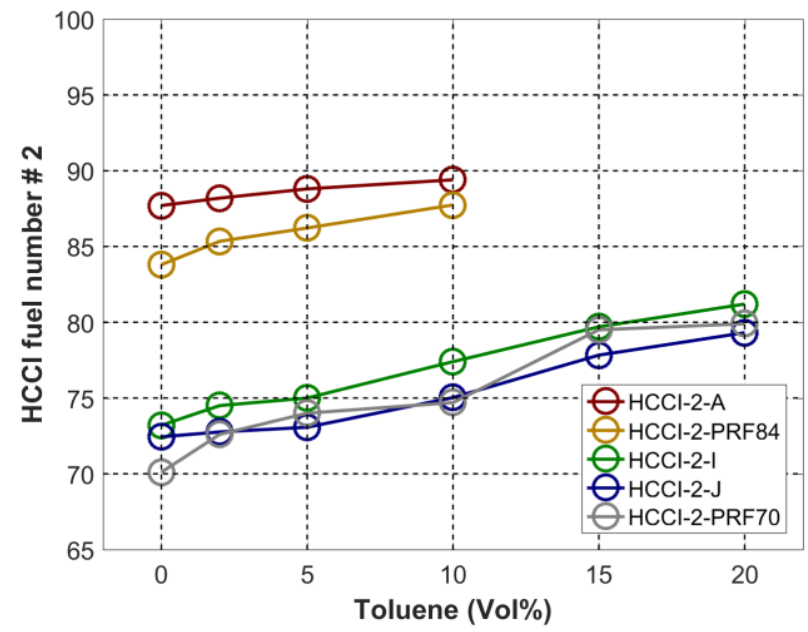

Figure 4: $\mathrm{HCCI}$ fuel number for FACE fuels, PRFs at $600 \mathrm{rpm}, \mathrm{T}_{\text {in }}=149^{\circ} \mathrm{C}$ and $\lambda=3$.

Figure 5 illustrates the variation of HCCI fuel number \# 3 with toluene addition. At this operating condition, the engine was running at 900 rpm with an inlet air temperature of $52^{\circ} \mathrm{C}$. With the increase in speed to $900 \mathrm{rpm}$, the increase in the HCCI fuel numbers remains about the same when compared to HCCI fuel number \# 1 . This is true for all base fuels. Both FACE A and PRF 84 have about the same HCCI fuel numbers at different toluene concentrations which shows that the composition effect is negligible at high engine speed for high ON fuels but for the low ON fuels, the compositional effect is significant. FACE $\mathrm{J}$ and I have about the same ON but the aromatic contents are higher for FACE J.

Page 4 of 12

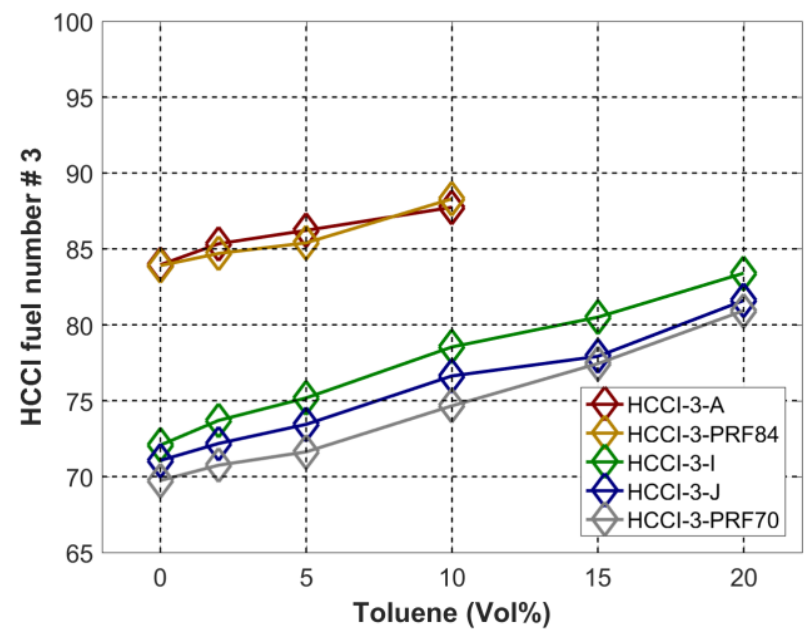

Figure 5: HCCI fuel number for FACE fuels, PRFs at $900 \mathrm{rpm}, \mathrm{T}_{\text {in }}=52^{\circ} \mathrm{C}$ and $\lambda=3$.

Figure 6 illustrates the variation of HCCI fuel number \# 4 with toluene addition. At this operating condition, the engine was running at 900 $\mathrm{rpm}$ with an inlet air temperature of $149^{\circ} \mathrm{C}$. With the increase in both speed and inlet air temperature, the changes in the HCCI fuel number is smaller with the addition of toluene except for FACE I. This is similar to the case of HCCI fuel number \# 2. It is certain that the increase in the inlet air temperature weakens the octane enhancement effect of toluene addition to base fuels.

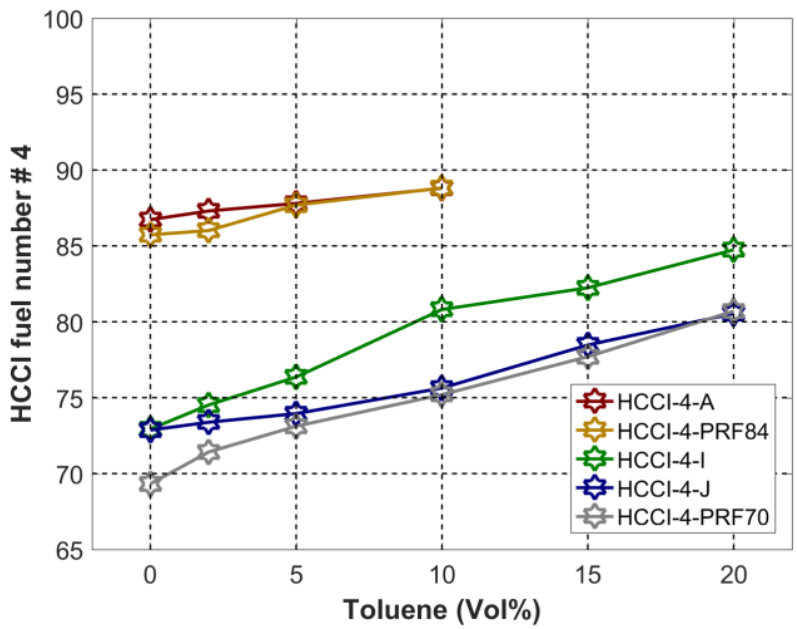

Figure 6: $\mathrm{HCCI}$ fuel number for FACE fuels, PRFs at $900 \mathrm{rpm}, \mathrm{T}_{\mathrm{in}}=149^{\circ} \mathrm{C}$ and $\lambda=3$.

Overall, it could be observed that the addition of toluene into the base fuel results in the increase of HCCI fuel number at all four $\mathrm{HCCl}$ conditions. The increase is observed to be greatest for low ON fuels as compared to high ON fuels. This is true for all four HCCI conditions. This is consistent with the previous study of ethanol addition into these five base fuels [15]. With the addition of ethanol into these base fuels, the increase in HCCI fuel number was greater compared to toluene addition into the same base fuels [15]. The octane enhancement effect of toluene addition is not as strong as it was observed to be for ethanol. For SI combustion, when octane booster is added to the base fuels, it is reported that a greatest increase in $\mathrm{ON}$ is seen for the low $\mathrm{ON}$ fuels 
[16]. In that sense, base fuels seems to behave similar both in stoichiometric and lean combustion conditions.

\section{Blending HCCI fuel number (BON)}

Figure 7 illustrates the Blending HCCI fuel number \# 1 for all five base fuels. The overall BON range for low ON fuels is from 90 to 145. PRF 70 has a higher BON as compared to FACE I and FACE J, showing the compositional effect on the blending behavior. The higher BON values for the PRF 70 indicates that toluene has a strong octane enhancement effect on PRF 70 than FACE I and FACE J. For the nonlinear behavior to exist, the blending HCCI fuel number has to be greater or less than 120 which is the $\mathrm{ON}$ of toluene. For $100 \%$ toluene, it is expected that the Blending HCCI fuel number will approach 120. At low concentrations, FACE I shows synergistic blending effect whereas FACE J shows antagonistic blending effect. With the increasing toluene concentration, non-linearity seems to vanish and blending HCCI fuel number remains somewhat constant and equal to be 120. For the high ON fuels, blending HCCI fuel number is somewhat constant and equal to 120 , which shows that the non-linear behavior does not exists for high ON fuels.

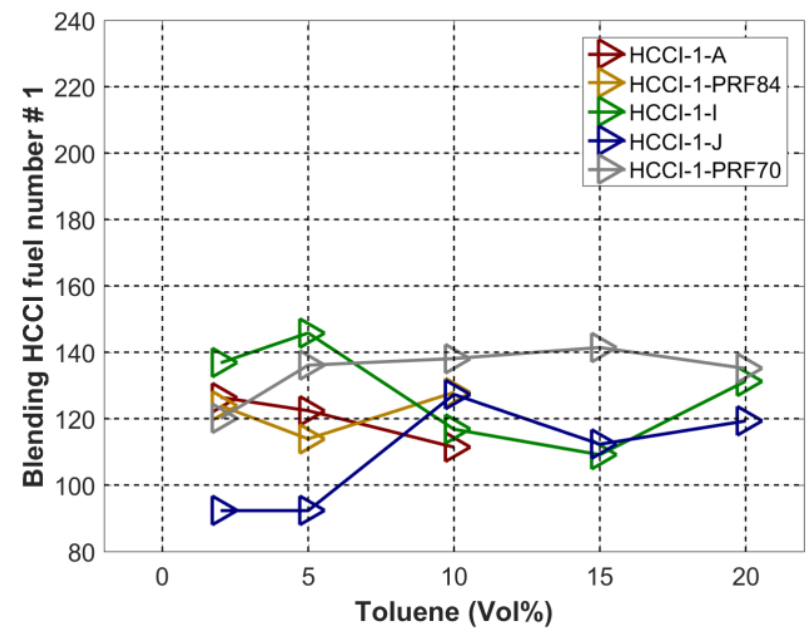

Figure 7 : Blending HCCI fuel numbers $(B O N \# 1)$ for toluene with FACE gasolines and PRFs as base fuels $\left(600 \mathrm{rpm}, \mathrm{T}_{\mathrm{in}}=52^{\circ} \mathrm{C}\right.$ and $\left.\lambda=3\right)$.

Figure 8 illustrates the Blending HCCI fuel number \# 2 for all five base fuels. The BON range has increased from 80 to 200 for low ON fuels. With an increase in the inlet air temperature, a non-linear blending behavior is observed at low concentrations for low ON fuels. At high toluene concentrations, the blending octane number for low octane base fuels seems to converge around 120 showing a somewhat weaker non-linear effect. FACE J shows the strongest antagonistic non-linear blending effect among the low ON fuel. Different slopes for low ON fuels show the compositional effect on blending behavior. The increase in inlet air temperature has resulted in a non-linear blending behavior for both FACE A and PRF 84 as compared to HCCI fuel number \# 1. PRF 84 has synergistic non-linear blending whereas FACE A has antagonistic effect, reflecting on the compositional effect.

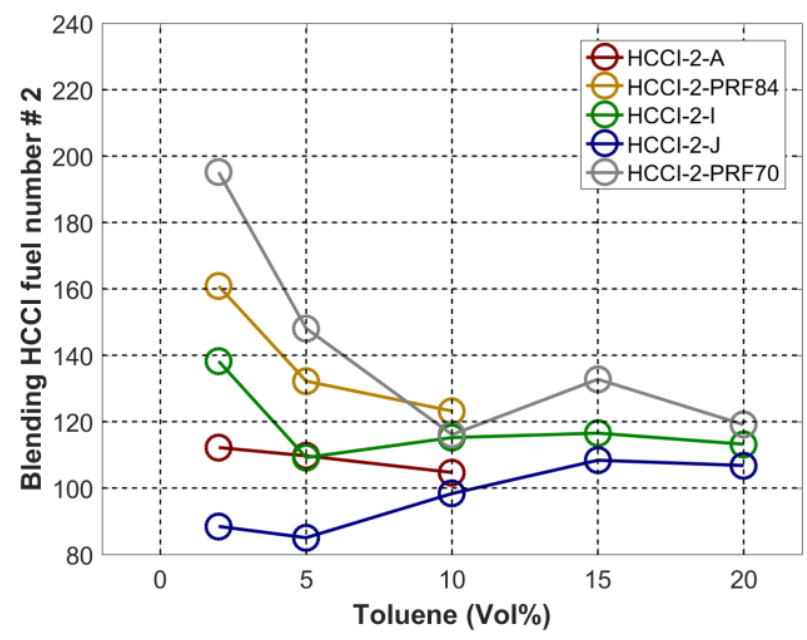

Figure 8 : Blending HCCI fuel numbers (BON \#2) for toluene with FACE gasolines and PRFs as base fuels $\left(600 \mathrm{rpm}, \mathrm{T}_{\mathrm{in}}=149^{\circ} \mathrm{C}\right.$ and $\left.\lambda=3\right)$.

Figure 9 illustrates the Blending HCCI fuel number \# 3 for all five base fuels. With the increase in engine speed to $900 \mathrm{rpm}$, a very weak nonlinear blending behavior or linear behavior is observed for all the base fuel at high toluene concentrations. FACE $\mathrm{J}$ has shown some improvement for the BON values when compared to HCCI \# 1 and 2 whereas BON values for PRF70 have reduced. The high octane fuels also seems to have BON value around 120 showing linear blending effect.

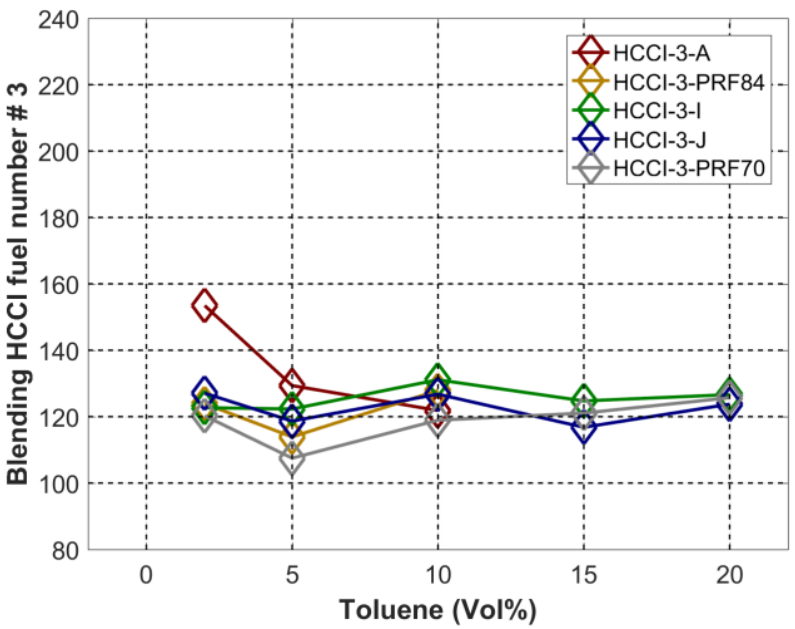

Figure 9 : Blending $\mathrm{HCCI}$ fuel numbers $(\mathrm{BON} \# 3)$ for toluene with FACE gasolines and PRFs as base fuels (900 rpm, $\mathrm{T}_{\text {in }}=52^{\circ} \mathrm{C}$ and $\lambda=3$ ).

Figure 10 illustrates the Blending HCCI fuel number \# 4 for all five base fuels. The increase in both the speed and inlet air temperature has significantly reduced the saturation behavior around ON 120 for all base fuels at high toluene concentrations as compared to other HCCI fuel numbers showing non-linear blending behavior. The BON range for low ON fuels is from 98 to 180 . The BON values for PRF 70 has been reduced where as an improvement in the $\mathrm{BON}$ values are observed for FACE I as compared to HCCI fuel number \# 1. FACE J has shown antagonistic non-linear blending effect at high concentrations, which is opposite to what was observed at HCCI fuel

Page 5 of 12 
number \# 1. FACE A and PRF 84 shows weak non-linear behavior with most of the data points scattered around 120.

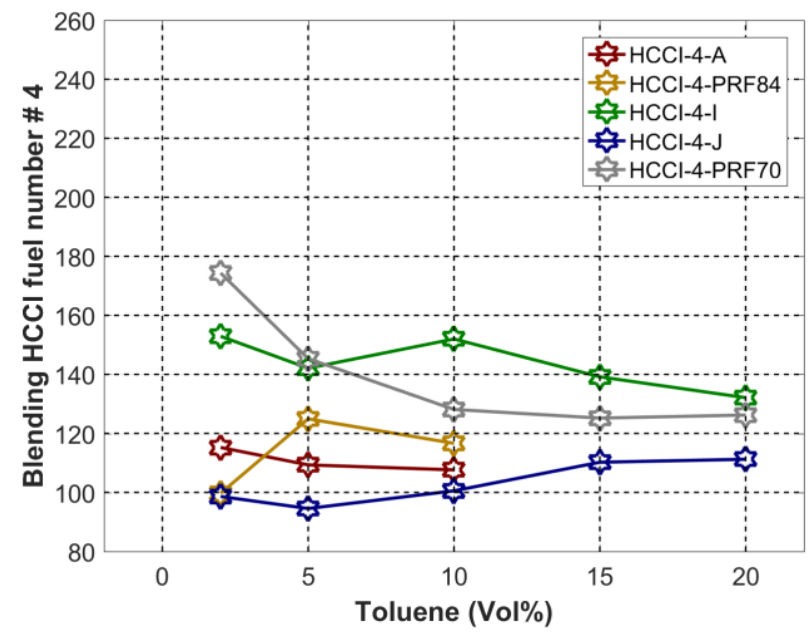

Figure 10 : Blending HCCI fuel numbers (BON \#4) for toluene with FACE gasolines and PRFs as base fuels (900 rpm, $\mathrm{T}_{\mathrm{in}}=149^{\circ} \mathrm{C}$ and $\lambda=3$ ).

\section{Effect of speed and temperature}

In this section, each of the base fuels has been shown separately in four different HCCI conditions. This will help to explain the effect of speed and temperature clearly for each of the base fuels. Figures 11, 12 and 13 presents the BON for FACE I, FACE J and PRF70, respectively. Among the three base fuels, one common observation is that at higher toluene concentrations either the non-linear blending effect is weak or there is no non-linear effect which means that the effect is linear and it can be concluded that toluene is not a strong octane booster. The degree of linearity is less observed for FACE I, which shows a scattered lines for all four HCCI conditions. FACE I and FACE J has ON close to 70 but different composition which leads to different BON values at different HCCI conditions highlighting the compositional effect on the blending behavior of toluene with the base fuels. The speed and temperature effect was negligible for FACE $\mathbf{J}$ at higher toluene concentrations. FACE I and PRF 70 have somewhat same BON range (105 to 150) at high toluene concentrations, which shows that both are behaving similarly. At high speed and low inlet air temperature higher BON is observed for FACE J than PRF 70.

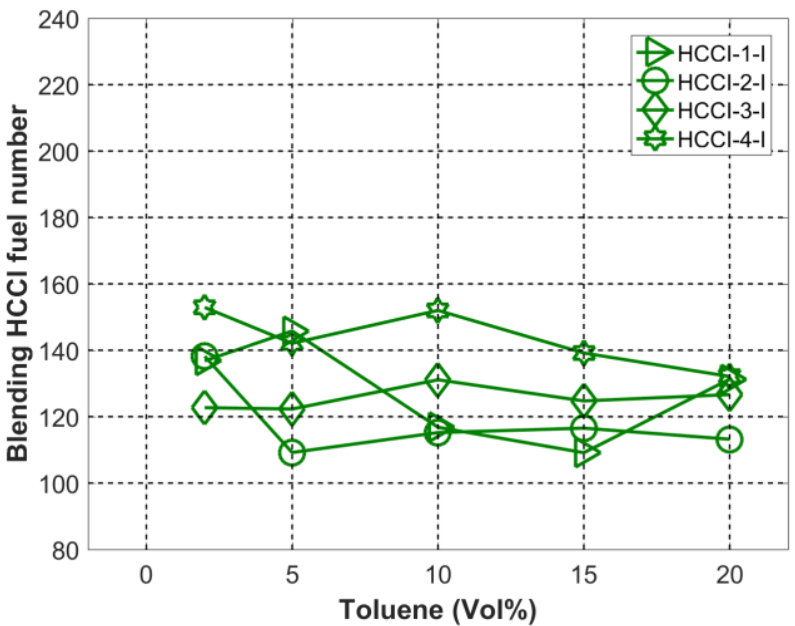

Figure 11: Blending HCCI fuel number (BON) for toluene with FACE I as base fuel, $\lambda=3$.

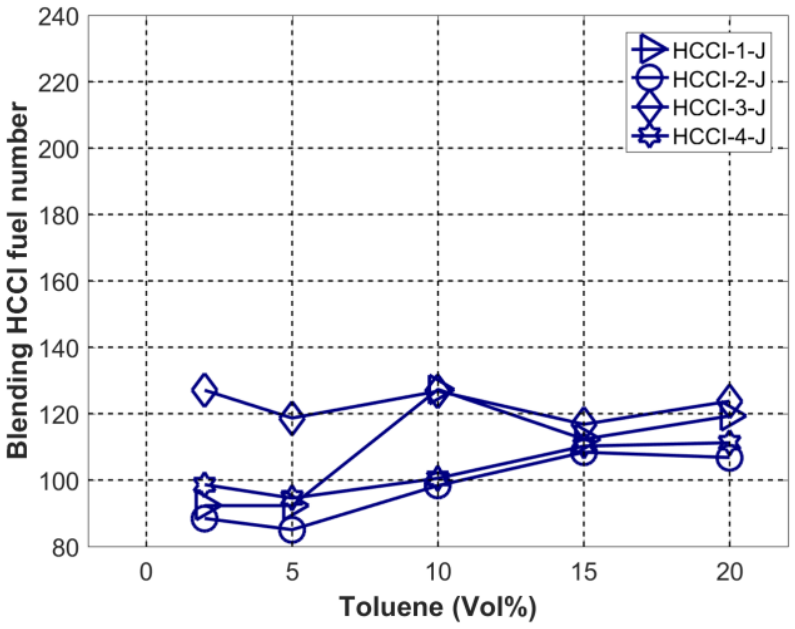

Figure 12: Blending HCCI fuel number (BON) for toluene with FACE J as base fuel, $\lambda=3$.

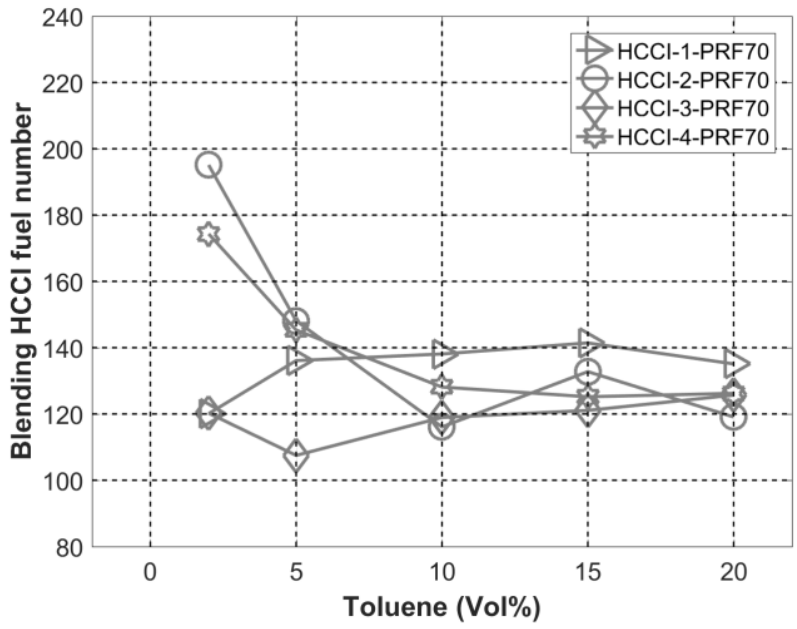

Figure 13: Blending $\mathrm{HCCI}$ fuel number (BON) for toluene with PRF 70 as a base fuel, $\lambda=3$.

Page 6 of 12 
Figures 14 and 15 presents the BON for the FACE A and PRF 84. Both the base fuels have same BON range from 100 to 160 . The BON values are closer to 120 showing linear blending or weak non-linear blending behavior for both base fuels except at low toluene concentrations. The saturation of BON values at high toluene concentrations shows that the effect of speed and temperature is negligible, which is true for both base fuels.

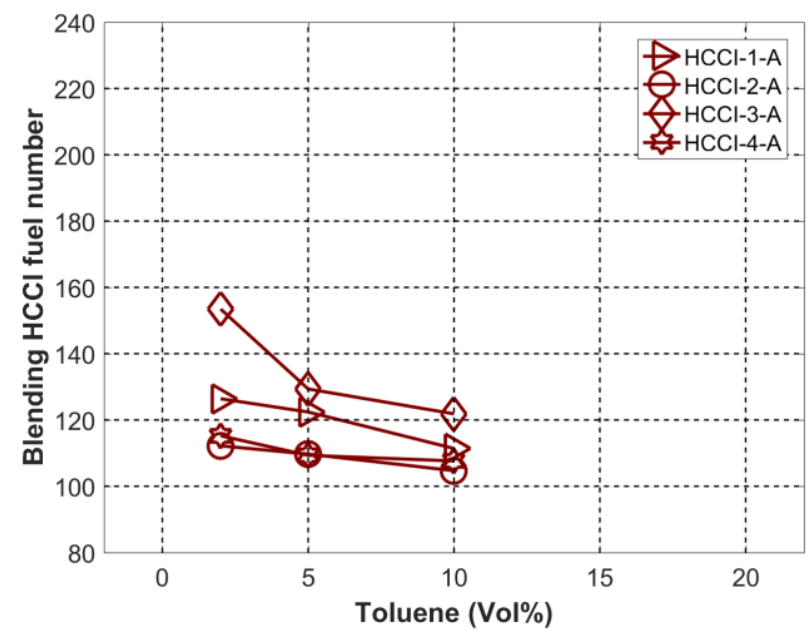

Figure 14: Blending HCCI fuel number (BON) for toluene with FACE A as base fuel, $\lambda=3$.

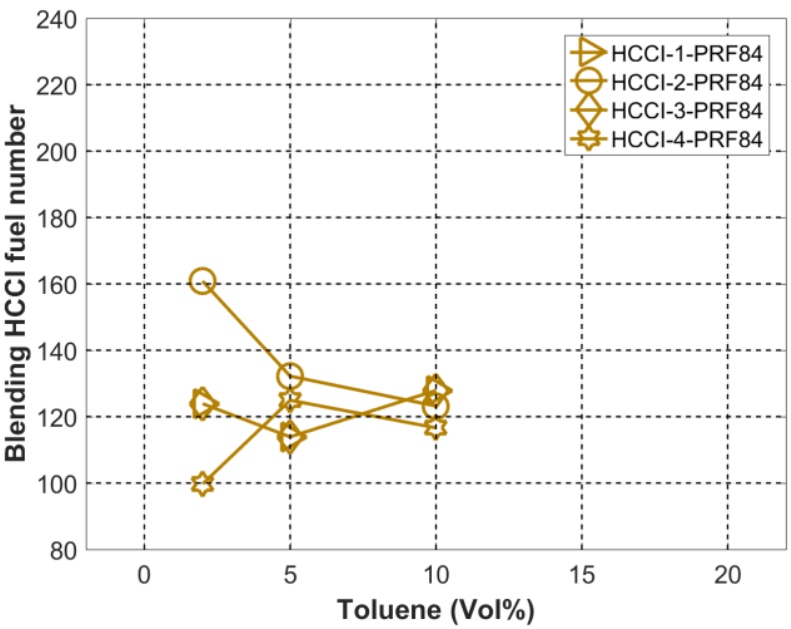

Figure 15: Blending HCCI fuel number (BON) for toluene with PRF 84 as base fuel, $\lambda=3$.

\section{Discussion}

It has been established that the fuel aromatics are important in determining the HCCI operating range [32]. The addition of aromatics, olefins and oxygenates into the commercial gasoline helps to increase the RON for SI combustion and hence anti-knock quality [33]. HCCI fuel number is used to characterize auto-ignition in the HCCI combustion mode as described earlier and the results obtained in this study highlights that the addition of toluene or aromatics to the base fuels in the lean combustion environment helps to increase the HCCI fuel number. It was found that the addition of ethanol or methanol resulted in greater increase of the HCCI fuel numbers for the same base fuels as compared to toluene $[15,24]$. This shows that ethanol and methanol still remains to be strong octane boosters as compared to toluene. Previous studies on ethanol for both volume and molar basis showed a large difference in the blending octane number [18]. At $20 \%$ ethanol concentration with FACE I and HCCI \# 1, on volume basis, BON was 193 and on mole basis was 132 [18]. This study with toluene on volume basis already shows that for most of the data, the blending octane number is close to 120 and if considered on molar basis using equation 3 and the measured data, there is not going to be a big difference in the blending octane number of toluene.

Toluene has a higher octane number when compared to neat ethanol or methanol. However, the higher latent heat of vaporization and the larger mole fractions for both ethanol and methanol results in a higher HCCI fuel number. For e.g. $20 \%$ volume of ethanol is equal to $38 \%$ by mole but for $20 \%$ toluene by volume it is about $25 \%$ by mole which could be the main reason why HCCI fuel number did not increase significantly with toluene addition.

Previous studies for HCCI combustion have highlighted that the addition of ethanol or methanol on the same base fuels results in synergistic blending effect i.e. the BON is higher than the $\mathrm{ON}$ of the ethanol or methanol $[15,24]$. The study with toluene shows both synergistic and antagonistic blending effect. For SI combustion, it has been observed that the addition of toluene into PRF mixtures results in antagonistic blending effect [11]. In that sense, there are experimental conditions where the addition of toluene into base fuels can result in the similar blending behavior at both SI and HCCI conditions.

\section{Conclusions}

The octane boosting effect of toluene addition to five base fuels (FACE I, FACE J, PRF 70, FACE A and PRF 84) corresponding to octane numbers of 70 and 84 was studied in HCCI conditions. Following are the conclusions from the experimental observations:-

- The non-linear blending effect with toluene addition can be explained by the blending octane number and is observed to be both synergistic and antagonistic blending effect depending on base fuel and experimental conditions.

- Toluene does not act as a strong octane booster. A weak nonlinear or linear blending with most of the BON values scattered around 120 explains this observation.

- At small concentrations, toluene is not as effective of an octane booster as ethanol or methanol. The small increase in HCCI fuel number at low toluene concentrations explains this observation.

- The base fuel composition and octane number plays an important role in the blending behavior of toluene. The blending octane number for toluene is lower for a base fuel with higher aromatic contents.

- $\quad$ Speed and inlet air temperature have secondary effects on the blending behavior of toluene. Each of the HCCI fuel numbers, representing certain speed and inlet air temperature, helped to investigate the effect of operating conditions on the blending behavior of toluene.

Page 7 of 12 


\section{References}

[1] Ramadan, A., Sarathy, SM., Khurshid, M., and Badra, J., "A blending rule for octane numbers of PRFs and TPRFs with ethanol," Fuel, 180: 175-186 , 2016, doi:10.1016/j.fuel.2016.04.032.

[2] Elfasakhany, A., "Investigations on the effects of ethanolmethanol-gasoline blends in a spark-ignition engine: performance and emissions analysis, ,Engineering Science and Technology, an International Journal, 18:4, 713-719, 2015, doi.org/10.1016/i.jestch.2015.05.003.

[3] Surisetty, V., Dalai, A., and Kozinski, J., "Alcohols as alternative fuels: An overview,"Applied Catalysis A: General, 404:11, 1-11 , 2011, doi.org/10.1016/j.apcata.2011.07.021.

[4] Boot, M., Tian, M., Hensen, E., Sarathy, SM. et al "Impact of fuel molecular structure on auto-ignition behaviorDesign rules for future high performance gasolines.," Progress in Energy and Combustion Science, 60, May 125, 2017, doi.org/10.1016/j.pecs.2016.12.001.

[5] Sarathy, SM., Farooq, A., and Kalghatgi, G., "Recent progress in gasoline surrogate fuels.,"Progress in Energy and Combustion Science., 65, March 67-108 , 2018, doi.org/10.1016/j.pecs.2017.09.004.

[6] ASTM D2699-13b, "Standard Test Method for Research Octane Number of Spark-Ignition Engine Fuel,"ASTM International, West Conshohocken, PA, 2013, doi: 10.1520/D2699.

[7] ASTM D2700-14, "Standard Test Method for Motor Octane Number of Spark-Ignition Engine Fuel,"ASTM International, West Conshohocken, PA, 2016, doi: 10.1520/D2700-16.

[8] Kalghatgi, G., "Fuel Anti-Knock Quality - Part I. Engine Studies," SAE Technical Paper 2001-01-3584, 2001, doi:10.4271/2001-01-3584.

[9] Andrae, J., Brinck, T., and Kalghatgi, G., "HCCI experiments with toluene reference fuels modeled by a semidetailed chemical kinetic model," Combustion and Flame, 2008, 155(4), 696-712. doi.org/10.1016/i.combustflame.2008.05.010.

[10] Andrae, J., Björnbom, P., Cracknell, R., and Kalghatgi, G., "Autoignition of toluene reference fuels at high pressures modeled with detailed chemical kinetics," Combustion and Flame, 2007, 149(1-2), 2-24. doi.org/10.1016/j.combustflame.2006.12.014.

[11] Morgan, N., Smallbone, A., Bhave, A., Kraft, M. et al., "Mapping surrogate gasoline compositions into RON/MON space ," Combustion and Flame, 2010, 157(6), 1122-1131, doi.org/10.1016/j.combustflame.2010.02.003.

[12] STP225-EB,"Knocking Characteristics of Pure Hydrocarbons ,"ASTM International, West Conshohocken, PA, 1958, doi.org/10.1520/STP225-EB.

[13] Heywood, J., 1988, "Internal Combustion Engine Fundamentals", McGraw Hill, New York, 1989.

[14] Foong, T., Morganti, K., Brear, M., Silva, G. et al., "The octane numbers of ethanol blended with gasoline and its surrogates," Fuel, 115: 727-739, 2014, doi:10.1016/j.fuel.2013.07.105.

[15] Waqas, M., Naser, N., Sarathy, SM., Morganti, K. et al., "Blending Octane Number of Ethanol in HCCI, SI and CI Combustion Modes," SAE Int. J. Fuels Lubr. 9(3):659-682, 2016, doi:10.4271/2016-01-2298.

[16] Rankovic, N., Bourhis, G., Loos, M., and Dauphin, R., "Understanding octane number evolution for enabling alternative low RON refinery streams and octane boosters as transportation fuels,"Fuel, 150: 41-47 , 2015, doi:10.1016/j.fuel.2015.02.005.

Waqas, M., Atef, N., Singh, E., MASURIER, J. et al., "Blending Behavior of Ethanol with PRF 84 and FACE A Gasoline in HCCI Combustion Mode," SAE Technical Paper 2017-24-0082, 2017, doi:10.4271/2017-24-0082. Waqas, M., Morganti, K., Masurier, J., and Johansson, B., "Blending Octane Number of Ethanol on a Volume and Molar Basis in SI and HCCI Combustion Modes," SAE Technical Paper 2017-01-2256, 2017, doi:10.4271/2017$\underline{01-2256}$.

Ng, H., and Charalamdides, A., " Alexandros G. Charalambides (2013). Homogenous Charge Compression Ignition (HCCI) Engines, Advances in Internal Combustion Engines and Fuel Technologies, InTech Open Access Publisher, 2013, doi: 10.5772/55807.

Aroonsrisopon, T., Foster, D., Morikawa, T., and Iida, M., "Comparison of HCCI Operating Ranges for Combinations of Intake Temperature, Engine Speed and Fuel

Composition," SAE Technical Paper 2002-01-1924, 2002, doi:10.4271/2002-01-1924.

Truedsson, I., Cannella, W., Johansson, B., and Tuner, M., "Development of New Test Method for Evaluating HCCI Fuel Performance," SAE Technical Paper 2014-01-2667, 2014, doi:10.4271/2014-01-2667.

Partridge, R., Weissman, W., Ueda, T., Iwashita, Y. et al., "Onboard Gasoline Separation for Improved Vehicle Efficiency," SAE Int. J. Fuels Lubr. 7(2):366-378, 2014, doi:10.4271/2014-01-1200.

Singh, E., Badra, J., Mehl, M., and Sarathy, S., "Chemical Kinetic Insights into the Octane Number and Octane Sensitivity of Gasoline Surrogate Mixtures.," Energy \& Fuels., 31(2), Feb 1945-1960 , 2017, doi10.1021/acs.energyfuels.6b02659.

Waqas, M., Naser, N., Sarathy, M., Feijs, J. et al., "AutoIgnition of Iso-Stoichiometric Blends of Gasoline-EthanolMethanol (GEM) in SI, HCCI and CI Combustion Modes," SAE Technical Paper 2017-01-0726, 2017,

doi:10.4271/2017-01-0726.

Singh, E., Waqas, M., Johansson, B., and Sarathy, SM., "Simulating HCCI Blending Octane Number of Primary Reference Fuel with Ethanol," SAE Technical Paper 201701-0734, 2017, doi:10.4271/2017-01-0734.

Cannella, W., Foster, F., Gunter, G., and Leppard, W., "FACE Gasolines and Blends with Ethanol: Detailed Characterization of Physical and Chemical Properties," CRC Report No AVFL-24, July, 2014.

Bhavani Shankar, V., Sajid, M., Al-Qurashi, K., Atef, N. et al., "Primary Reference Fuels (PRFs) as Surrogates for Low Sensitivity Gasoline Fuels," SAE Technical Paper 2016-01-0748, 2016, doi:10.4271/2016-01-0748.

Sarathy, S., Kukkadapu, G., Mehl, M., Wang, W. et al, "Ignition of alkane-rich FACE gasoline fuels and their surrogate mixtures," Proceedings of the Combustion Institute, 35: 249-257, 2015, doi:10.1016/j.proci.2014.05.122. Ahmed, A., Goteng, G., Shankar, V., Al-Qurashi, K. et al, "A computational methodology for formulating gasoline surrogate fuels with accurate physical and chemical kinetic properties," Fuel, 143: 290-300, 2015,

doi:10.1016/j.fuel.2014.11.022.

Chen, C., Wang, Z., Dagaut, P., and Sarathy, S., "Jet-stirred reactor oxidation of alkane-rich FACE gasoline fuels.,"

Page 8 of 12 
Proc. Combust. Inst., 36(1), Dec 517-524 , 2017, doi.org/10.1016/j.proci.2016.05.040.

[31] Sarathy, S., Kukkadapu, G., Mehl, M., Javed, T. et al "Compositional effects on the ignition of FACE gasoline fuels.," Combustion and Flame, 169, April 171-193, 2016, doi.org/10.1016/j.combustflame.2016.04.010.

[32] Lacey, J., Filipi, Z., Sathasivam, S., Cannella, W. et al., "HCCI Operability Limits: The Impact of Refinery Stream Gasoline Property Variation,"J. Eng. Gas Turbines Power 135(8), 081505 ,Jul 05, 2013, doi: 10.1115/1/4024260.

[33] Kalghatgi, G., "Fuel/engine interactions", SAE International, 2014, doi:10.4271/R-409.

\section{Contact}

Prof. Bengt Johansson

Bengt.Johansson@kaust.edu.sa

\section{Acknowledgements}

The experimental facilities were provided by the Clean Combustion Research Center and the author is quite thankful for the support. The paper was published with the funding from King Abdullah University of Science and Technology (KAUST) and Saudi Aramco.

\section{Definitions/Abbreviations}

$\begin{array}{ll}\text { BON } & \text { Blending Octane Number } \\ \text { CAD } & \text { Crank Angle Degree } \\ \text { CA50 } & \text { Crank Angle for } 50 \% \text { heat release } \\ \text { CFR } & \text { Cooperative Fuel Research } \\ \text { FACE } & \text { Fuels for Advanced Combustion Engines } \\ \text { HCCI } & \text { Homogeneous Charge Compression Ignition } \\ \text { MON } & \text { Motor Octane Number } \\ \text { ON } & \text { Octane Number } \\ \text { PRFs } & \text { Primary Reference Fuels } \\ \text { RON } & \text { Research Octane Number } \\ \text { SI } & \text { Spark Ignition } \\ \text { TDC } & \text { Top Dead Center }\end{array}$




\section{Appendix A}

It was found that for small changes in HCCI fuel number, large changes can result for BON. For this purpose uncertainty analysis was performed on the BON values. Four different average errors were estimated from Figure 2 corresponding to each HCCI fuel numbers. A maximum average error of 0.25 was found for HCCI \# 4 and as a worst case scenario, uncertainty analysis was only performed for HCCI \# 4 . For the estimation of an error, line of best fit was used. For e.g. for the blend of PRF 60, HCCI fuel number by default equal to 60 and by using the line of best fit, it was estimated around 60.1 for HCCI \# 4 giving an error of 0.1. In a similar fashion, an error was estimated for other data points on the line of best fit and then an average of 0.25 was estimated.

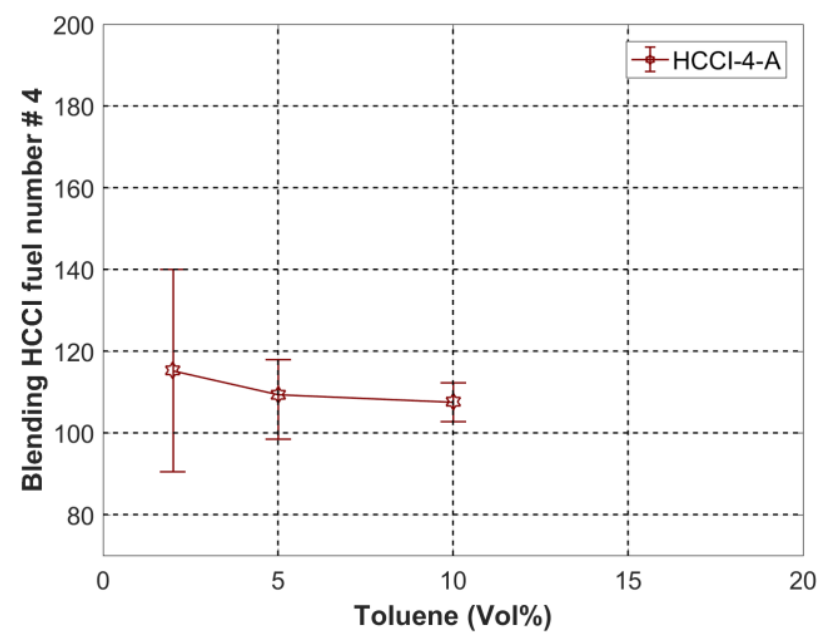

Figure A1 : Uncertainty analysis on Blending HCCI fuel numbers (BON \#4) for toluene with FACE A as base fuels $\left(900 \mathrm{rpm}, \mathrm{T}_{\text {in }}=149^{\circ} \mathrm{C}\right.$ and $\left.\lambda=3\right)$.

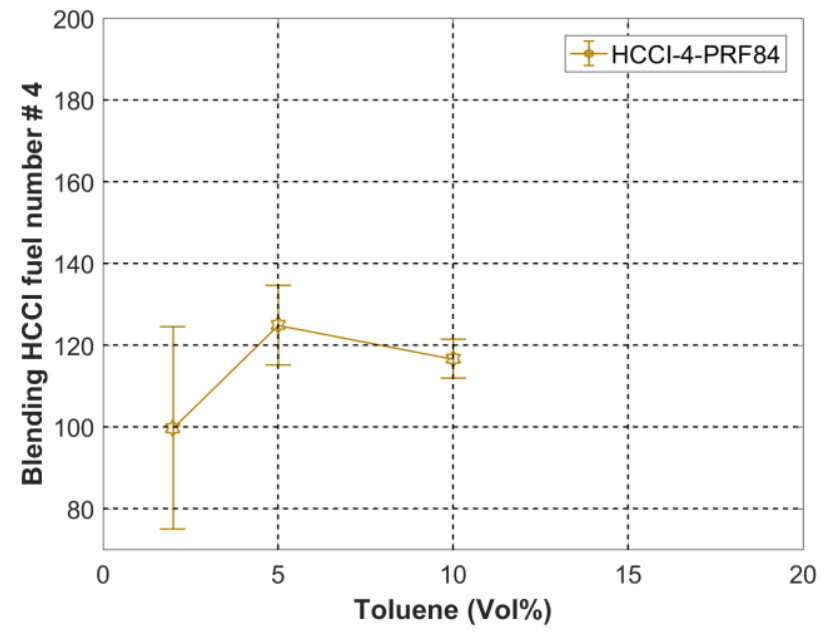

Figure A2 : Uncertainty analysis on Blending HCCI fuel numbers (BON \#4) for toluene with PRF 84 as base fuels $\left(900 \mathrm{rpm}, \mathrm{T}_{\mathrm{in}}=149^{\circ} \mathrm{C}\right.$ and $\left.\lambda=3\right)$.

Page 10 of 12 


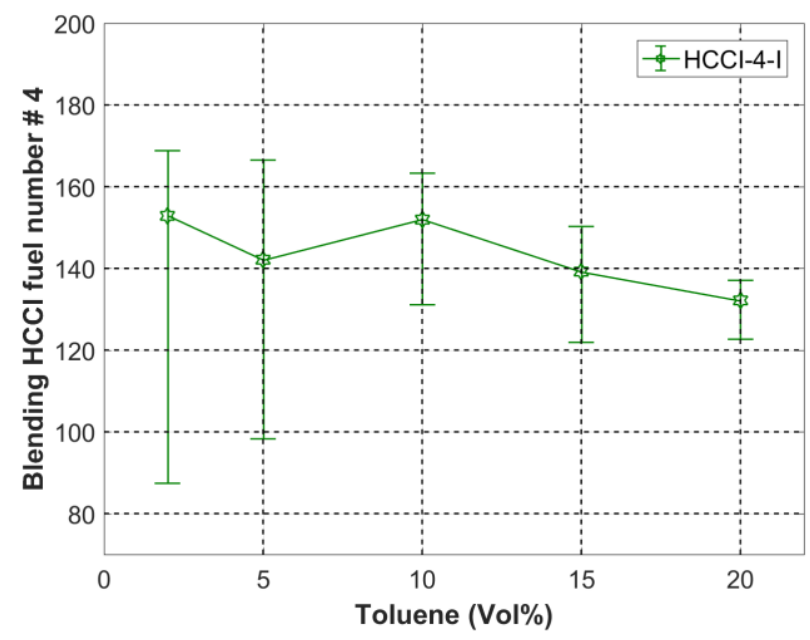

Figure A3: Uncertainty analysis on Blending HCCI fuel numbers (BON \#4) for toluene with FACE I as base fuels $\left(900 \mathrm{rpm}, \mathrm{T}_{\text {in }}=149^{\circ} \mathrm{C}\right.$ and $\left.\lambda=3\right)$.

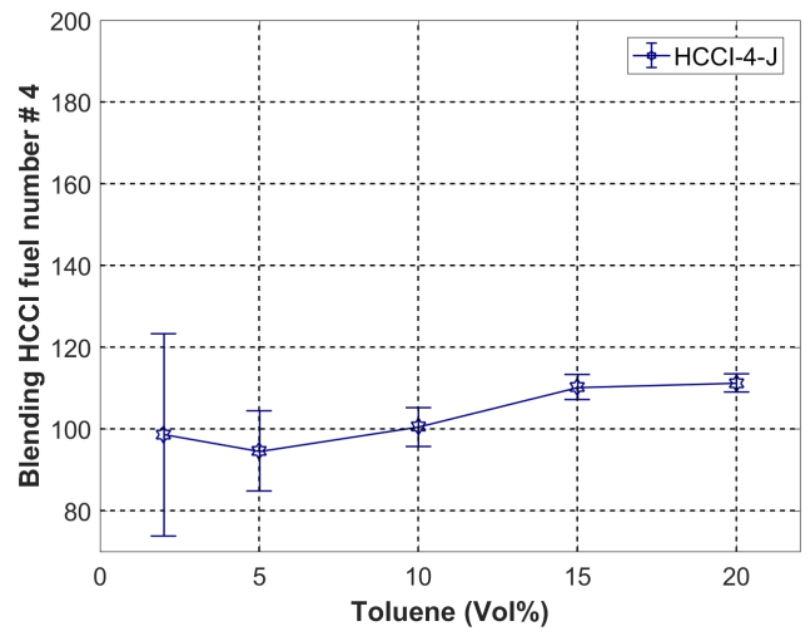

Figure A4: Uncertainty analysis on Blending $\mathrm{HCCI}$ fuel numbers (BON \#4) for toluene with FACE J as base fuels $\left(900 \mathrm{rpm}, \mathrm{T}_{\mathrm{in}}=149^{\circ} \mathrm{C}\right.$ and $\left.\lambda=3\right)$.

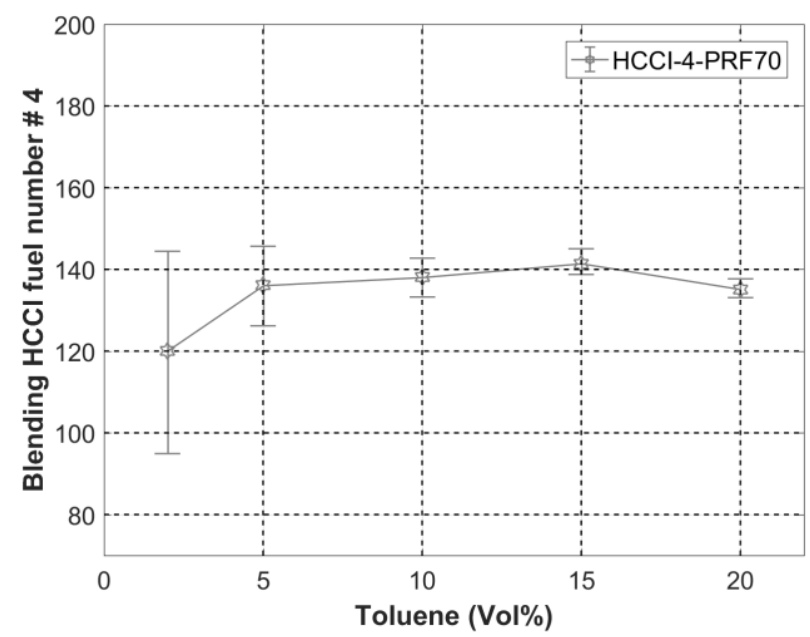

Figure A5: Uncertainty analysis on Blending HCCI fuel numbers (BON \#4) for toluene with PRF 70 as base fuels $\left(900 \mathrm{rpm}, \mathrm{T}_{\text {in }}=149^{\circ} \mathrm{C}\right.$ and $\lambda=3$ ).

Page 11 of 12 


\section{Appendix B}

Table A1: Values of constant in equation 2 for four HCCI fuel numbers

\begin{tabular}{|l|l|l|l|}
\hline $\begin{array}{l}\text { Operating } \\
\text { conditions }\end{array}$ & $\mathrm{x}$ & $\mathrm{y}$ & $\mathrm{z}$ \\
\hline HCCI-1 (RON) & -0.7999 & 27.966 & -151.45 \\
\hline HCCI-2 & -0.8351 & 26.601 & -120.73 \\
\hline HCCI-3 & -0.4083 & 17.448 & -91.459 \\
\hline HCCI-4 (MON) & -0.3959 & 16.513 & -72.929 \\
\hline
\end{tabular}

Page 12 of 12 